\title{
UTILIZAÇÃO DE IMAGENS LANDSAT 8 (OLI) PARA MAPEAMENTO DE ÁREAS CULTIVÁVEIS COM ARROZ NO ESTADO DE SANTA CATARINA - BRASIL, SAFRA 2014/2015 E 2015/2016
}

\author{
Miriam Rodrigues da Silva ${ }^{(\mathrm{a})}$, Cristiane Batista Salgado ${ }^{(\mathrm{b})}$, Nickolas Castro Santana $^{(\mathrm{c})}$ \\ (a)Universidade de Brasília - UnB/GEA/LSIE/ Campus Universitário Darcy Ribeiro, Asa Norte - 70.910-900, \\ Brasília, DF, Brasil. / miriamsibmol@gmail.com \\ (b)Universidade de Brasília - UnB/GEA/LSIE/ Campus Universitário Darcy Ribeiro, Asa Norte - 70.910-900, \\ Brasília, DF, Brasil. / nanesalgado@gmail.com \\ (c)Universidade de Brasília - UnB/GEA/LSIE/ Campus Universitário Darcy Ribeiro, Asa Norte - 70.910-900, \\ Brasília, DF, Brasil. / nickolasantana2011@gmail.com
}

\section{Eixo: GEOTECNOLOGIAS E MODELAGEM ESPACIAL EM GEOGRAFIA FÍSICA}

\begin{abstract}
Resumo
O objetivo principal deste trabalho foi mapear e dar consistência às estimativas e previsões de produção de arroz no Estado de Santa Catarina e acompanhar a expansão ou retração da cultura, por meio das imagens Lansdat 8 . A metodologia consistiu nos seguintes procedimentos: seleção de cenas de imagem Landsat 8 (OLI), processamento digital, segmentação, interpretação visual, trabalho de campo e validação dos dados. Foram obtidos dois mapas de ocupação de arroz irrigado, um para o ano safra 2014/2015 e outro para 2015/2016. A validação do mapeamento com o índice Kappa mostrou um alto nível de concordância dos dados. Este mapeamento detectou uma redução no plantio da cultura em relação ao ano anterior, provando ser eficiente porque acompanhou a retração da cultura. A análise temporal do Landsat 8 (OLI) foi essencial para diferenciar a dinâmica das culturas e para interpretar o cultivo do arroz.
\end{abstract}

Palavras chaves: arroz, estimativa, previsão de safra, segmentação, índice Kappa,

\section{Introdução}

A cultura do arroz é explorada em todos os continentes, pois faz parte da dieta básica da população mundial. Ocupa a terceira posição em produção de área de cultivo, perdendo apenas para o milho e trigo. Na Ásia concentra-se $90 \%$ da produção e consumo, sendo responsável por 5\% das importações e $62 \%$ das exportações mundiais. Os 12 maiores países produtores de arroz estão localizados neste continente. A América do Sul é o segundo maior produtor e o terceiro em termos de consumo de arroz. O Brasil é o maior produtor do continente, responsável por 54\% da produção, seguido da Colômbia, com 9,4\% (AZAMBUJA et al., 2002).

Segundo o IBGE (2016), a Região Sul do país é responsável por 64\% da produção nacional de arroz, sendo que o Estado do Rio Grande do Sul é o maior produtor nacional com 55\%, e Santa Catarina com $7 \%$. 
Estes dois Estados usam a técnica de cultivo de arroz irrigado, conseguindo maior produtividade do que o cultivo de arroz sequeiro. No entanto, no Estado de Santa Catarina ocorre uma maior distinção, pois o sistema de cultivo de arroz é $100 \%$ pré-germinado. Uma das principais vantagens deste modo de produção é a elevação da produtividade, em razão do sistema de semeadura ser realizado em lâmina de água, com sementes pré-germinadas (EPAGRI, 2015).

Segundo Klering et al. (2009), a dimensão de áreas cultivas no país, colabora para que a metodologia utilizada por instituições oficiais tenha um alto grau de subjetividade, porque é baseado em questionários aplicados aos agricultores e entidades associadas a prática agrícola. Atualmente, é necessário obter informações precisas e em tempo hábil, sobre a produção agrícola, para que os órgãos do governo possam organizar e decidir prioridades, tanto para a política de preços e controle dos estoques reguladores.

Assim, o uso do sensoriamento remoto com o auxílio do Sistema de Informação Geográfica (SIG) transformou-se em uma ferramenta para mapeamentos de culturas agrícolas no país. Diante disso, tem se desenvolvido estudos com metodologias mais objetivas para o mapeamento, monitoramento e previsão da cultura de arroz, por meio de coleta, processamento, análise e disponibilização de informações geográficas (D'ARCO et al, 2006; KLERING et al 2013; OZDOGAN, 2010; JIN et al, 2015; KONTGIS et al, 2015; MOSLEH et al, 2015).

O principal objetivo deste trabalho é mapear e dar consistência nas estimativas e previsões da produção de arroz no Estado de Santa Catarina e acompanhar a expansão ou retração da cultura, por meio das imagens Lansdat 8 (OLI).

\section{Metodologia de Trabalho}

O Estado de Santa Catarina está localizado na Região Sul do país (Figura 1), e representa 3,2\% da produção agrícola nacional (IBGE, 2016). 

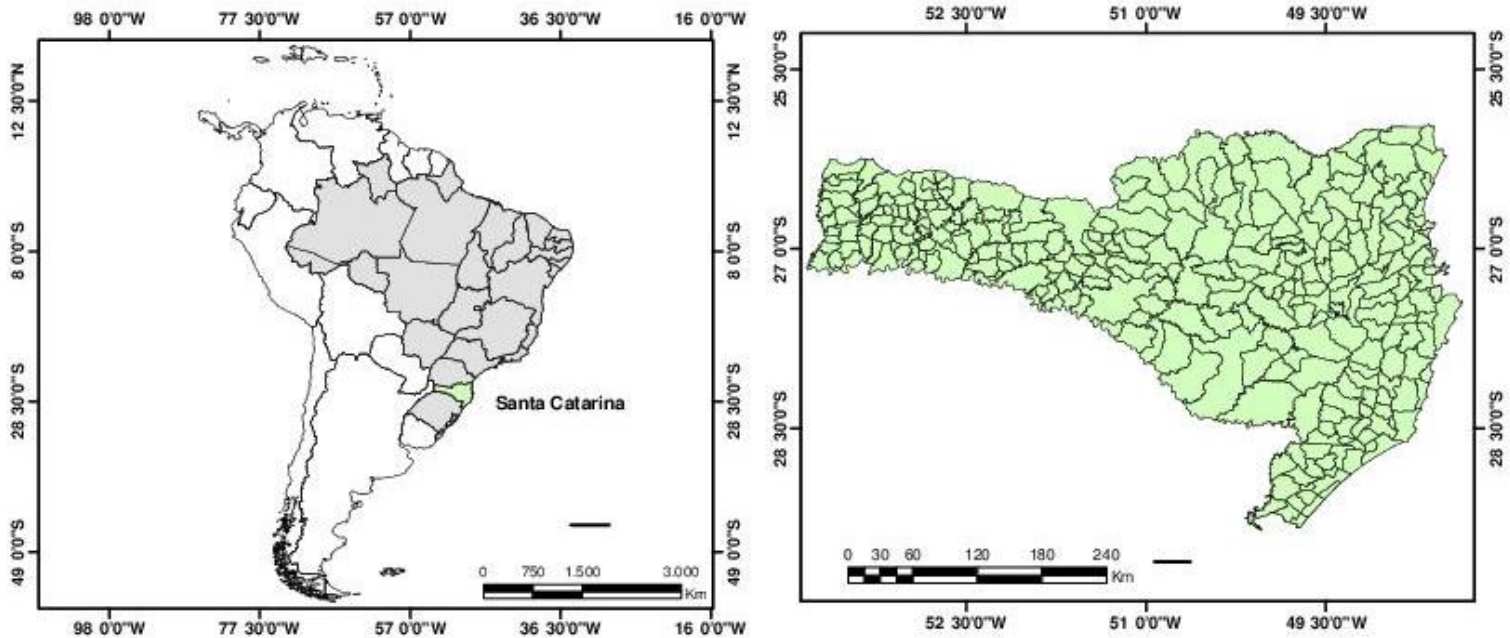

Figura1 - Localização da área de estudo

Para a realização deste trabalho foram utilizados os seguintes procedimentos metodológicos: (a) seleção da cena da imagem Landsat 8 (OLI), (b) processamento digital, (c) segmentação, (d) interpretação visual, (e) trabalho de campo e, (f) validação do mapeamento.

Foram selecionadas 4 cenas do Landsat 8 (OLI): 220/78,79,80 e 221/79. Estas imagens foram escolhidas sem cobertura ou com pouca cobertura de nuvens no período de agosto de 2014 a junho de 2015 e de agosto de 2015 a junho de 2016, correspondendo ao ano safra 2014/2015 e 2015/2016. Este período mencionado refere-se ao inicio de plantio e colheita da cultura de arroz na região. Foram selecionadas somente imagens das áreas municipais em que ocorre o plantio de arroz. Posteriormente, foi realizado o processamento digital das imagens composto pelos seguintes passos: conversão da resolução radiométrica, composição de bandas, fusão e recorte.

Na conversão da resolução radiométrica o range de 16 bits foi convertido para 8 bits, para facilitar a distribuição em diferentes softwares e o tamanho do arquivo foi reduzido pela matade. Assim, os níveis de cinza das bandas espectrais ficaram distribuídos na faixa de 0-255, que é similar aos produtos Lansat 5 e Landsat 7.

Para este trabalho foi utilizada a composição colorida com as bandas $6,5,4$, que possui resultado equivalente aos antecessores do Landsat 5 e 7 (composição 5,4,3). E para se obter uma imagem de melhor resolução espacial, fusionou-se as bandas de 30 metros com a banda 8 que possui 15 metros de resolução espacial. Posterior a fusão, a imagem foi recortada no limite da região produtora de arroz no Estado de Santa Catarina.

No processamento das imagens para mapear as áreas de arroz irrigado no Estado de Santa Catarina, foi utilizado a metodologia de segmentação de imagem no módulo ENVI Feature Extraction, sendo segmentado o recorte das áreas onde ocorrem o plantio de arroz. 


\section{OS DESAFIOS DA GEOGRAFIA FÍSICA NA FRONTEIRA DO CONHECIMENTO \\ Instituto de Geociências - Unicamp \\ Campinas - SP \\ 28 de Junho à 02 de Julho de 2017}

A segmentação é a fragmentação de uma imagem em regiões contínuas e similares, com características semelhantes em termos de brilho, textura, cor e entre outros (NASCIMENTO e ALMEIDA FILHO, 1996; MOREIRA e SOUZA, 2001; VASCONCELOS e NOVO, 2004; NAKAMURA e NOVO, 2005). Com este procedimento se obtêm polígonos com aparência natural e uma delimitação próxima ao que é gerado manualmente por um profissional.

O ENVI Feature Extraction pode ser usado para extrair diferentes tipos de feições terrestres: construções, estradas, pontes, cursos de rios, delimitação de lagos, vegetação, agricultura, com base nas características espaciais e espectrais das imagens pancromáticas e multiespectrais. Esta fase do procedimento é composta pela segmentação, fusão, refinamento e contagem dos atributos, onde os pixels com valores e características similares são agrupados de acordo com as informações espacial, espectral e de textura (ENVI, 2015). O nível de escala (scale level), aplicado na ferramenta "ENVI Feature Extraction", foi de 70. O valor empregado para a reunião dos segmentos (merging segments) em subgrupos foi de 90 .

Após a segmentação do recorte do Estado de Santa Catarina, onde ocorrem os plantios de arroz, o arquivo foi exportado em polígonos no formato shapefile. Posteriormente, a fim de se obter um mapeamento mais preciso, foram selecionados manualmente por meio da interpretação visual, no Argcis 9.3, somente os polígonos que pertenciam a classe de arroz. Esta interpretação foi realizada cena a cena, seguindo uma escala de visualização fixa e utilizando imagens Landsar 8 (OLI) de diferentes datas (Figura 2).

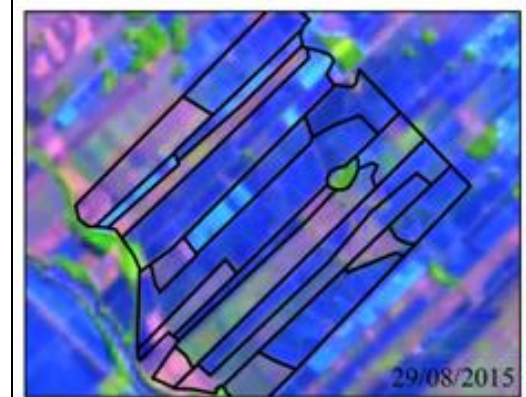

Padrão de cor azul: fase de plantio

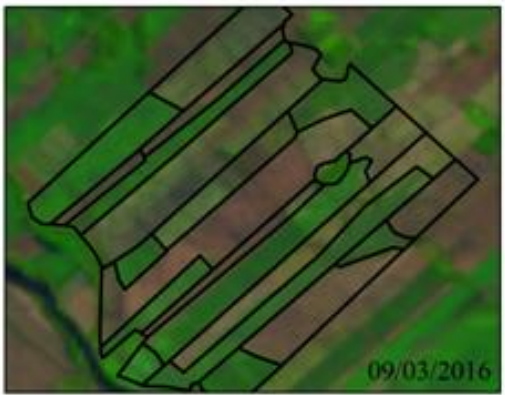

Padrão de cor marrom: fase de colheita

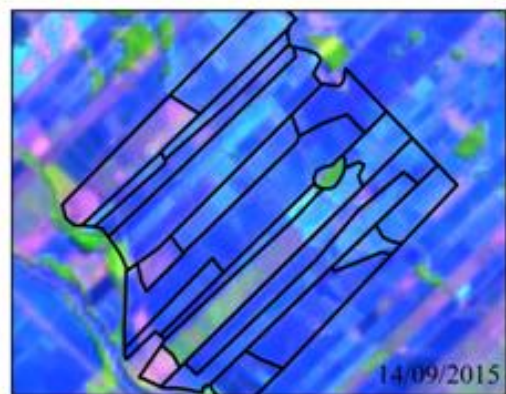

Padrào de cor azul: fase de plantio

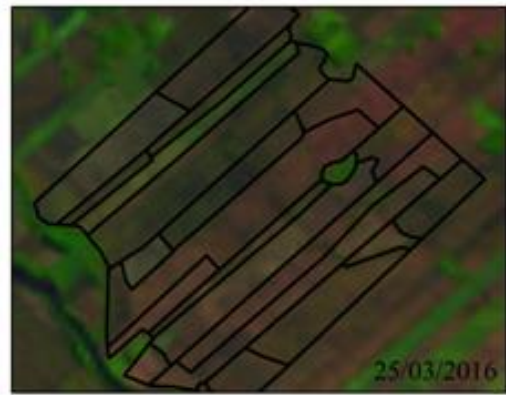

Padrão de cor marrom: fase de colheita

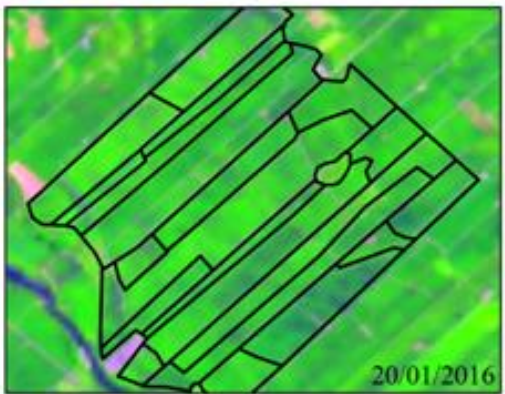

Padrão de cor verde: fase de vigor vegetativo e enchimento de grãos

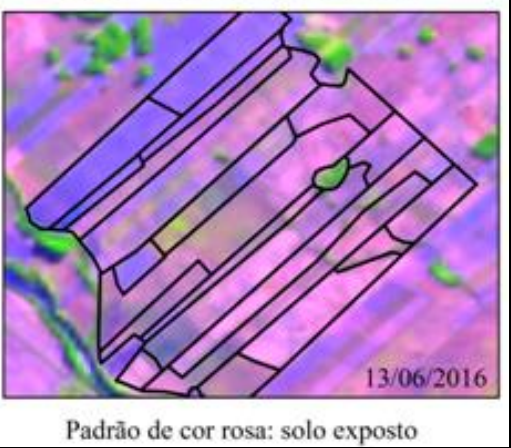




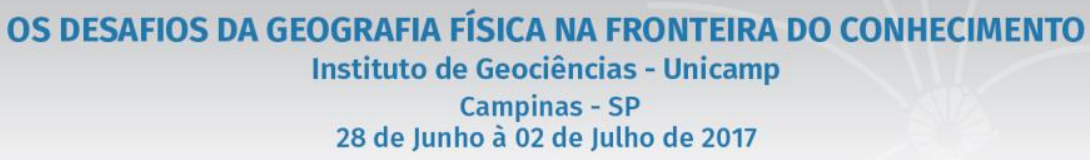

Figura 2 -Imagens que auxiliaram na interpretação do mapeamento Fonte: Landsat 8 (OLI), RGB 654

Para auxiliar o mapeamento de arroz no Estado de Santa Catarna, foi realizado um trabalho de campo pelos técnicos da CONAB (Companhia Nacional de Abastecimento) nos principais municípios produtores de arroz (Figura 3). Estes dados foram coletados usando um receptor GPS com uma antena externa e um micro portátil, este ligado a um transformador conectado na bateria do veículo. Foi utilizado o software GTM (GPS-Track-Maker) para captar em tempo real as coordenadas das lavouras de arroz e outras informações relevantes, como áreas ocupadas com milho, pastagem e várzeas. Foram coletados 159 pontos georreferenciados de arroz, que estavam próximos das estradas. Também foram coletados de forma aleatória nas imagens Landsat 8 (OLI), 91 pontos de não arroz.

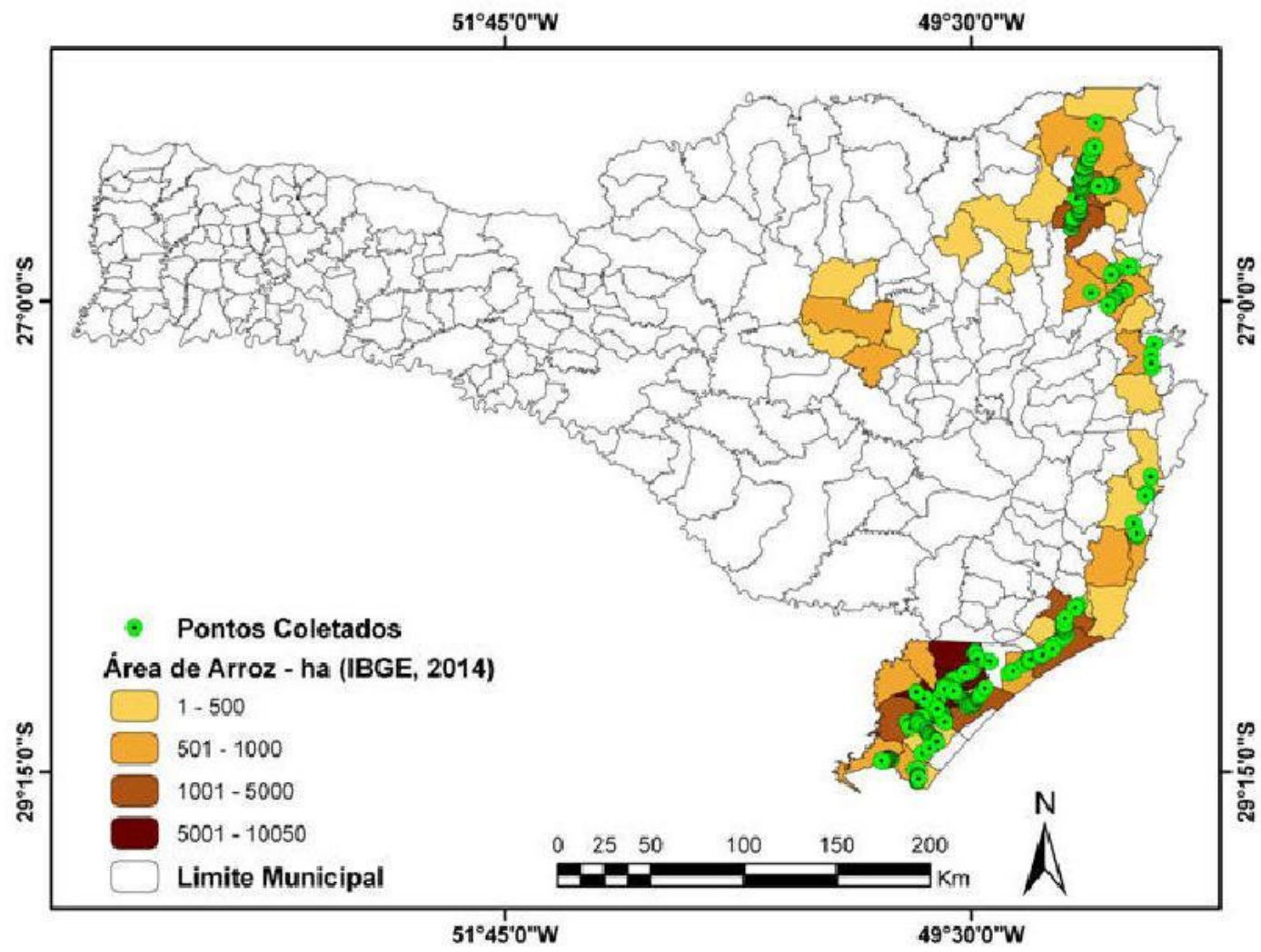

Figura 3 - Pontos coletados em campo.

Com estes 250 pontos coletados foram calculados a matriz de confusão e o índice Kappa, para medir o desempenho do mapeamento. Segundo Antunes e Lingnau (2004), para avaliar o mapeamento com imagens de sensoriamento remoto, o coeficiente de acurácia Kappa é o mais indicado, porque leva em consideração os erros de comissão e omissão da matriz de erros.

\section{Resultados e discussão}

Após seleção dos polígonos que pertenciam a classe de arroz, foram obtidos 2 mapas de ocupação de arroz irrigado para o Estado de Santa Catarina, um para o ano safra 2014/2015 e outro 2015/2016 
XVII Simpósio Brasileiro de Geografia Física Aplicada

I Congresso Nacional de Geografia Física

\section{OS DESAFIOS DA GEOGRAFIA FÍSICA NA FRONTEIRA DO CONHECIMENTO \\ Instituto de Geociências - Unicamp \\ Campinas - SP \\ 28 de Junho à 02 de Julho de 2017}

(Figura 4 e 5). O tamanho das áreas mapeadas foram calculados e comparados com os dados de produção do IBGE e CONAB (Tabela 1). Com o uso da geotecnologia, o método para coletar os dados é direto, as áreas de plantio de arroz são caracterizadas pontualmente na imagem, enquanto que as estimativas do IBGE e da CONAB são adquiridos por meio de metodologias subjetivas.

Tabela I - Estimativa da área com arroz no Estado de Santa Catarina (hectare)

\begin{tabular}{c|c|c|c|c|c|c}
\hline Estado & $\begin{array}{c}\text { IBGE } \\
(\mathbf{2 0 1 4 / 2 0 1 5 )}\end{array}$ & $\begin{array}{c}\text { IBGE } \\
\mathbf{2 0 1 5 / 2 0 1 4 )}\end{array}$ & $\begin{array}{c}\text { CONAB } \\
(\mathbf{2 0 1 4 / 2 0 1 5 )}\end{array}$ & $\begin{array}{c}\text { CONAB } \\
(\mathbf{2 0 1 5 / 2 0 1 6})\end{array}$ & $\begin{array}{c}\text { Mapemaneto } \\
(\mathbf{2 0 1 4} / \mathbf{2 0 1 5})\end{array}$ & $\begin{array}{c}\text { Mapeamento } \\
(\mathbf{2 0 1 5} / \mathbf{2 0 1 6})\end{array}$ \\
\hline $\begin{array}{c}\text { Santa } \\
\text { Catarina }\end{array}$ & 148.706 & 147.483 & 147.900 & 147.400 & 151.786 & 147.817 \\
\hline
\end{tabular}

De acordo com a tabela 2, verifica-se uma redução nas áreas de arroz irrigado para o ano safra 2015/2016. Segundo os dados do IBGE (2016), a redução foi 0,82\%, e a CONAB (2016) de 0,33\% em relação a safra anterior, no mapeamento esta redução foi de 2,61\%. Segundo a CONAB (2016), houve uma redução na área plantada em quase todos os estados produtores devido ao excesso de chuvas e baixa luminosidade, que ocasionou plantio fora da janela ideal, resultando na necessidade de replantio de algumas lavouras de arroz.

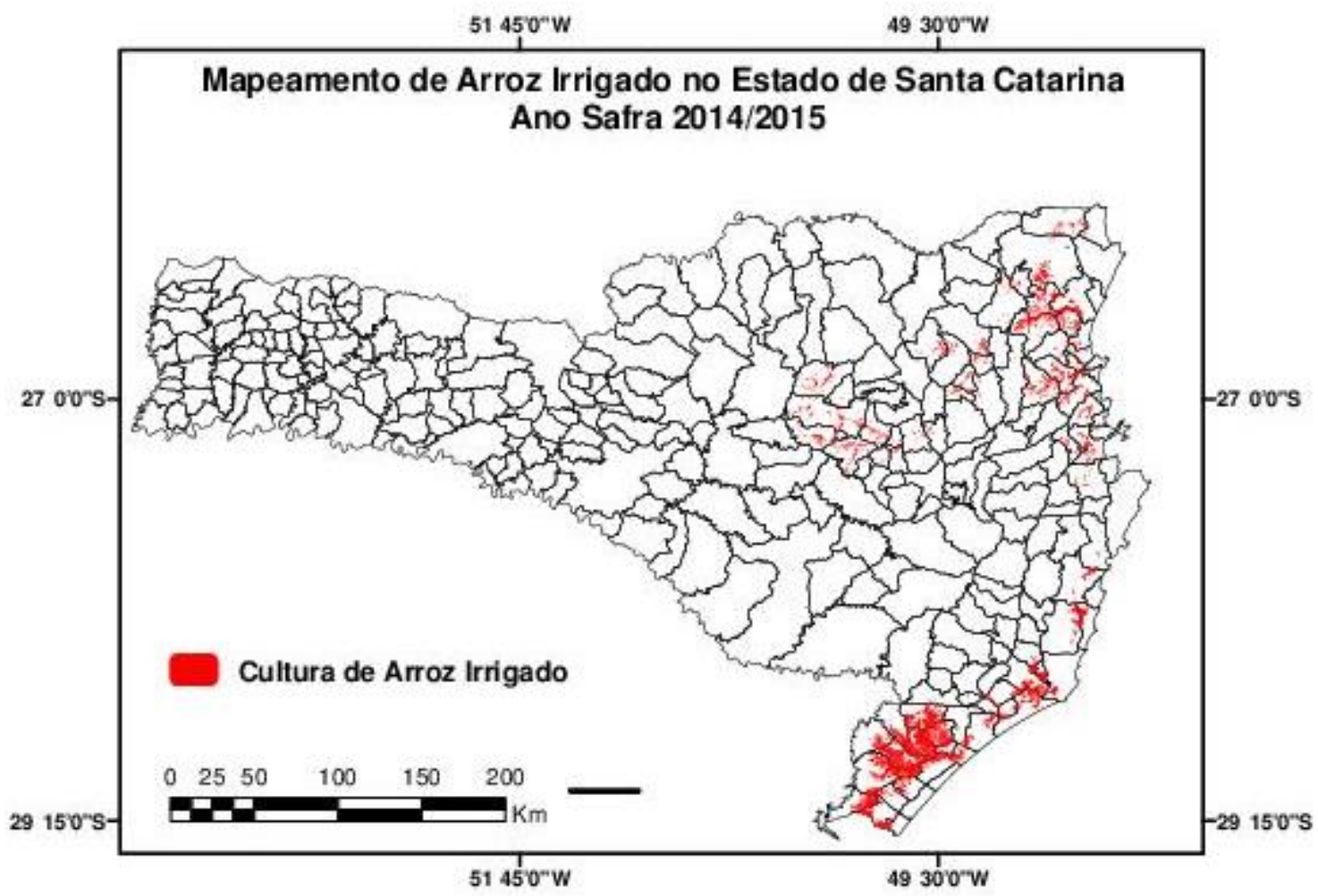

Figura 4 - Áreas mapeadas com arroz irrigado no Estado de Santa Catarina safra 2014/2015 
XVII Simpósio Brasileiro de Geografia Física Aplicada

I Congresso Nacional de Geografia Física

\section{OS DESAFIOS DA GEOGRAFIA FÍSICA NA FRONTEIRA DO CONHECIMENTO \\ Instituto de Geociências - Unicamp \\ Campinas - SP \\ 28 de Junho à 02 de Julho de 2017}

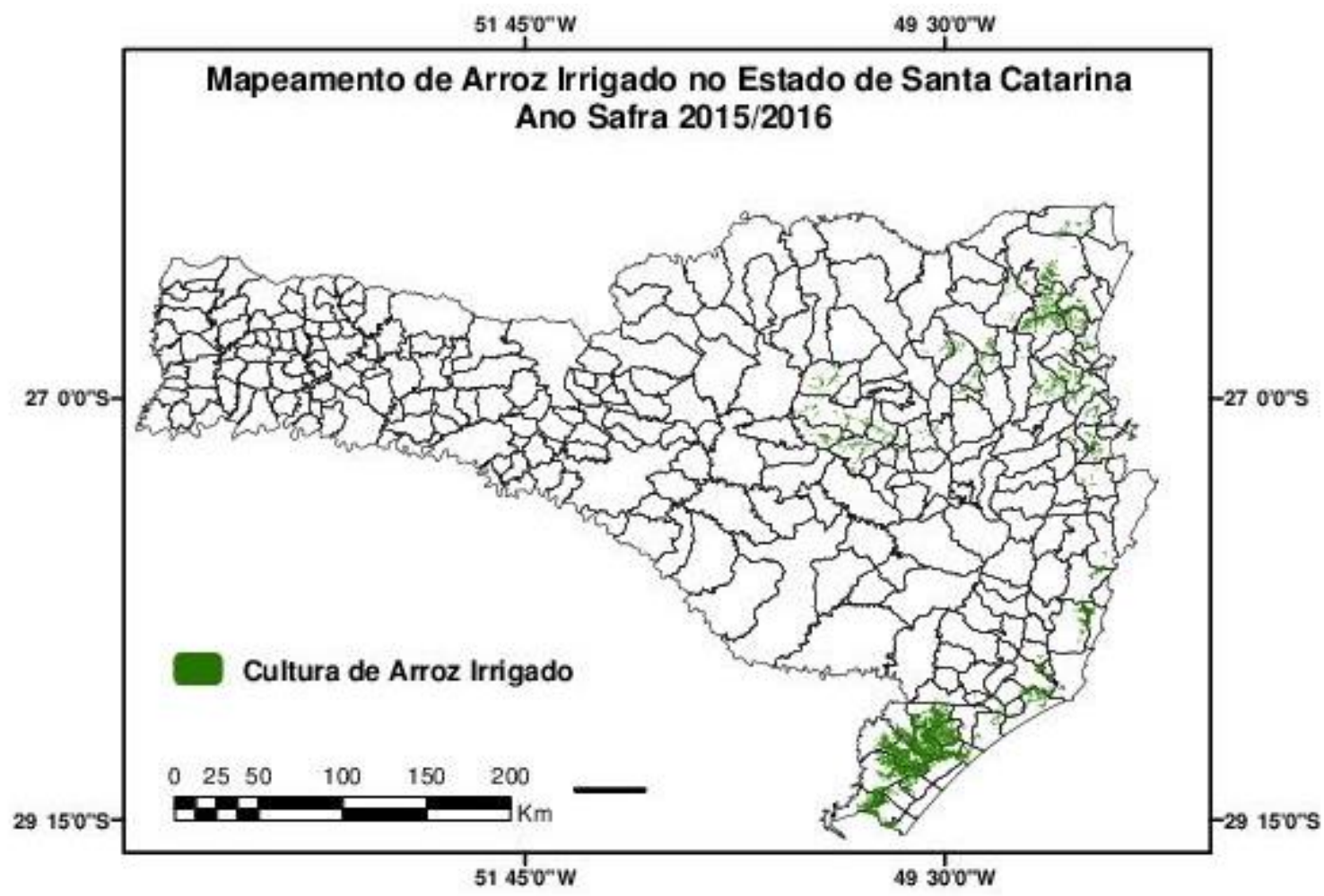

Figura 5 - Áreas mapeadas com arroz irrigado no Estado de Santa Catarina safra 2015/2016

Analisando os dados coletados em campo e comparando os mapas da classificação com as imagens Landsat 8 (OLI), verifica-se que o mapeamento ano safra 2014/2015 obteve uma exatidão global de 95\% e o coeficiente Kappa de 0,90, o mapeamento ano safra 2015/2016, obteve uma exatidão global de $91 \%$ e o coeficente Kappa de 0,82. indicando um alto nível de concordância dos dados (Tabela 2).

Tabela II - Matriz de confusão

\begin{tabular}{l|c|c|c|l|c|c|c}
\hline $\begin{array}{l}\text { Mapeamento } \\
\mathbf{2 0 1 4 / 2 0 1 5}\end{array}$ & Arroz & Não-Arroz & Total & $\begin{array}{l}\text { Mapemento } \\
\mathbf{2 0 1 5 / 2 0 1 6}\end{array}$ & Arroz & $\begin{array}{c}\text { Não- } \\
\text { Arroz }\end{array}$ & Total \\
\hline Arroz & 149 & 1 & 150 & Arroz & 140 & 2 & 142 \\
\hline Não-Arroz & 10 & 90 & 100 & Não-Arroz & 19 & 89 & 108 \\
\hline Total & 159 & 91 & 250 & Total & 159 & 91 & 250 \\
\hline $\begin{array}{l}\text { Erro de } \\
\text { Omissão }\end{array}$ & $10 / 159$ & $1 / 91$ & - & $\begin{array}{l}\text { Erro de } \\
\text { Omissão }\end{array}$ & $19 / 159$ & $2 / 91$ & - \\
\hline $\begin{array}{l}\text { Erro de } \\
\text { Comissão }\end{array}$ & $1 / 150$ & $10 / 100$ & - & $\begin{array}{l}\text { Erro de } \\
\text { Comissão }\end{array}$ & $2 / 142$ & $19 / 108$ & - \\
\hline $\begin{array}{l}\text { Precissão } \\
\text { Global }\end{array}$ & $95 \%$ & $\begin{array}{l}\text { Índice } \\
\text { Kappa }\end{array}$ & 0,90 & Precissão Global & $91 \%$ & $\begin{array}{l}\text { Índice } \\
\text { Kappa }\end{array}$ & 0,82 \\
\hline
\end{tabular}

A avaliação por meio da matriz de confusão mostrou que os erros de omissão do mapeamento ano safra 2014/2015 foram de 6,28\% para a classe de arroz e 1,09\% para a classe de não arroz, significando que 1 ponto de arroz foi mapeado erroneamente. Os erros de comissão indicam os pontos 
que foram inseridos inadequadamente em uma classe. Sendo assim, observa-se na tabela 2 que, 6,6\% da classe de não-arroz foram inseridas incorretamente na classe de arroz, e $10 \%$ de classe de arroz foram incluídas na classe de não arroz. Os erros de omissão do mapeamento ano safra 2015/2016 foram de 11,95\% para a classe de arroz e 2,20\% não-arroz, e os erros de comissão foram de 1,41\% de não-arroz e $17,59 \%$ de arroz.

Estes mapeamentos realizados com as imagens Landsat 8 (OLI) mostraram que é possível o uso do sensoriamento remoto para auxiliar nas estimativas oficias. Isto se confirma no estudo de Jin et al. (2015), que utilizaram o Landsat para mapeamento de campos de arroz em escala regional. Outro estudo com imagens Landsat mostrou que é possível mapear arrozais com mais de $90 \%$ de precisão geral, onde os erros de omissão e comissão variaram de 6 a 25\%, e também salientaram que os dados deste satélite constataram mudanças na plantação de arroz e nos diferentes tipos cíclicos de cultivos anuais (KONTGIS et al., 2015). Da mesma forma, Campos et al. (2015), encontraram um resultado satisfatório com o uso do Landsat para o mapeamento de arroz, e indicaram que é possível estimar a cultura ainda no estadio inicial do seu clico de desenvolvimento, permintindo subsidiar as estimativas oficiais de forma antecipada e objetiva.

\section{Conclusões}

A partir do uso das imagens Landsat 8 (OLI) com o método de segmentação de imagens, foi possível gerar dados de estimativas de áreas cultivadas com arroz, bem próximos aos das estimativas oficiais, para os anos safras 2014/2015 e 2015/2016. O uso do método se mostrou adequado pelo excelente desempenho, com um índice Kappa de 0,90 e 0,82 respectivamente. E ainda constatou uma redução de $2,61 \%$ do plantio da safra de arroz irrigado em relação ao ano anterior, destacando que acompanhou a retração da cultura.

A análise com as imagens temporal do Landsat 8 (OLI) foi essencial para diferenciar a dinâmica da cultura e para interpretar o cultivo de arroz. Desta forma, sugeri-se um futuro acompanhamento nas áreas produtoras de arroz do Estado de Santa Catarina, para monitorar a expansão ou retração da cultura, com o objetivo de melhorar o mapeamento e tornar este instrumento um auxílio para as estimativas de produção anual de arroz.

\section{Agradecimentos}

A CONAB pelo apoio e por fornecer os pontos georreferenciados das lavouras de arroz. 


\section{Bibliografia}

ANTUNES, A. F. B.; LINGNAU, C. Analise de acuracia de mapa de uso do solo oriundo de classificação de imagem de alta resolução. Boletim de Ciências Geodésicas (Impresso), v. Vol 4, p. 101-113, 2004.

AZAMBUJA, I. H. V.; MAGALHÃES JR, A. M.; VERNETTI JÚNIOR, F. J. Situação da cultura do arroz no Mundo e no Brasil. (Série Culturas, Arroz). 2002.

CAMPOS, P. M.; LIMA, F. A. S.; SOUZA, A. L. F. de; OLIVEIRA, D.; LIMA, F. M.; FERNANDES, L. B.; HANEMANN, L.; PIFFER, T. R. de O. Mapeamento do arroz irrigado no Estado do Rio Grande do Sul Safra 2013/2014. 2015. In: XVII Simpósio Brasileiro de Sensoriamento Remoto, 2015, p. 1463-1469.

CONAB - Companhia Nacional de Abastecimento. Acompanhamento da safra brasileira de grãos. 2016. v. 3 - Safra 2015/16, n. 10 - Décimo levantamento, Brasília, p. 1-179, jul. 2016.

D'ARCO, E.; AlvarengA, B. S.; RIZZI, R.; RUDORFF, B. F. T.; MOREIRA, M. A.; ADAMI, M. Geotecnologias na estimativa da área plantada com arroz irrigado. Revista Brasileira de Cartografia, v. 58, n.3, p. 247-253, 2006.

ENVI. Tutorial ENVI FX: classificação por regra / segmentação orientada ao objeto. Disponível em: http://xa.yimg.com/kq/groups/17314041/1168582786/name/modulo_envifx_.pdf. Acesso em 10 dez. 2015.

EPAGRI - Empresa de Pesquisa Agropecuaria e Extensao Rural de Santa Catarina. Histórico da produção de arroz irrigado. Disponível em: http://www.epagri.sc.gov.br/index.php?option=com_content\&view=article\&id=84. Acesso em: 10 dez. 2015.

IBGE - Instituto Brasileiro de Geografia e Estatística. Levantamento sistemático da produção agrícola. Rio de

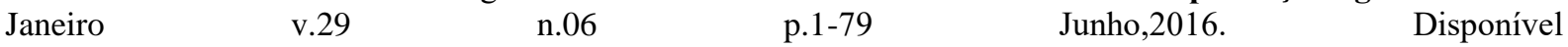
em:http://www.ibge.gov.br/home/estatistica/indicadores/agropecuaria/lspa/lspa_201606.pdf. Acesso em: 05 jun. 2016.

INSTITUTO CEPA/EPAGRI. Síntese Anual da Agricultura de Santa Catarina. v. 31. p. 82 - 97. Florianópolis, 2010. $10 \mathrm{dez} .2015$.

JIN, C., XIAO, X., DONG, J., QIN, Y. E WANG, Z. Mapping paddy rice distribution using multi-temporal Landsat imagery in the Sanjiang Plain, northeast China. Frontiers of Earth Science, v. 10, n. 1, p. 49-62, 2015

KLERING, E. V.; FONTANA, D. C.; ALVES, R. C. M.; ROCHA, J. V.; BERLATO, M. A. Estimativa de área cultivada com arroz irrigado para o Estado do Rio Grande do Sul a partir de imagens MODIS. Ciência e Natura, v. 35, p. 126-135, 2013.

KLERING, E. V.; GUTTERRES, D.; FONTANA, D. C.; BERLAT, O, M. A. Comparação entre os perfis temporais de arroz irrigado das coleções MODIS V004 e V005 para a região orizícola do Rio Grande do Sul. In: XIV Simpósio Brasileiro de Sensoriamento Remoto, Natal, p. 239-245, 2009.

KONTGIS, C.; SCHNEIDER, A.; OZDOGAN, M. Mapping rice paddy extent and intensification in the Vietnamese Mekong River Delta with dense time stacks of Landsat data. Remote Sensing of Environment, v. 169 , p. 255-269, 2015.

MOREIRA. M. A.; SOUZA, I. M. Análise de resultados de segmentação por crescimento de regiões em diferentes técnicas de processamento digital dedados do LANDSAT/TM para mapeamento de áreas cafeeiras. In: X Simpósio Brasileiro de Sensoriamento Remoto, Foz do Iguaçu, p. 21-26, 2001.

MOSLEH, M.; HASSAN, Q.; CHOWDHURY, E. Application of Remote Sensors in Mapping Rice Area and Forecasting Its Production: A Review. Sensors, v. 15, n. 1, p. 769-791, 2015.

NAKAMURA, J. C. S.; NOVO, E. M. L. M. Mapeamento da mancha urbana utilizando imagens de média resolução: sensores CCD/CBERS2 e TM/Landsat5 - estudo de caso da cidade de Rio Branco-Acre. In: XII Simpósio Brasileiro de Sensoriamento Remoto, Goiânia. INPE, 2005. p. 3843-3850, 2005.

NASCIMENTO, P. S. R.; ALMEIDA FILHO, R. Utilização da técnica de segmentação em imagens TM/LANDSAT visando otimizar a técnica da interpretação visual. In: Simpósio Brasileiro de Sensoriamento Remoto, Salvador - Ba. Inpe/Selper, 1996. 
OZDOGAN, M. The spatial distribution of crop types from MODIS data: temporal unmixing using independent component analysis. Remote Sensing of Environment, vol. 114, p.1190-1204, 2010.

VASCONCELOS, C. H.; NOVO, E. M. L. M. Mapeamento do uso e cobertura da terra a partir da segmentação e classificação de imagens fração solo, sombra e vegetação derivadas do modelo linear de mistura aplicado a dados do sensor TM/LANDSAT5, na região do reservatório de Tucuruí-PA. Acta Amazônica (Impresso), Manaus, v. 34, p. 487-493, 2004. 